\title{
Psicodinâmica do Trabalho do Coletivo de Profissionais de Educação de Escola Pública
}

\author{
Fernanda Sousa Duarte - Universidade de Brasilia, Brasilia, Brasil \\ Ana Magnólia Bezerra Mendes - Universidade de Brasília, Brasília, Brasil
}

\begin{abstract}
Resumo
Considerando o atual contexto da educação básica pública brasileira, o presente estudo teve como objetivo investigar as estratégias de mobilização coletiva de uma equipe de profissionais da educação de uma escola pública de ensino fundamental do Distrito Federal sob a perspectiva da Psicodinâmica do trabalho, abordagem que considera tal mobilização como um meio de ressignificar as vivências de sofrimento em prazer no trabalho. Foi utilizada a metodologia dejouriana. Para tal, foram realizadas observações não sistemáticas, análises documentais e seis sessões coletivas com 12 trabalhadores - professores regentes, professores em desvio de função e orientadora educacional - de uma mesma escola. Pode-se concluir que as estratégias de defesa individuais são predominantes e que a mobilização coletiva entre os profissionais de diferentes atribuições é prejudicada pela falta de um espaço público de discussão onde possam debater sobre suas angústias e prazeres cotidianos do trabalho.
\end{abstract}

Palavras-chave: Trabalho, educação, escola.

Psychodynamics of Work of Education Professionals in Public School

\begin{abstract}
Given the current context of Brazilian public basic education, the present study aimed to investigate the strategies of collective mobilization in professionals of education at a public elementary school of Distrito Federal, Brazil, from the perspective of psychodynamics of work, which considers such mobilization as a way to reframe the experience of suffering into pleasure at work. We used the dejourian methodology, using non-systematic observations, documentary analysis and six collective nonstructured interviews with 12 workers - school teachers, teachers in other functions and the educational advisor - from the same school it could be concluded that the individual defense strategies are predominant and the collective mobilization among professionals from different tasks is impaired by the lack of a public discussion where they can discuss their anxieties and pleasures of everyday work.

Keywords: Work, education, school.
\end{abstract}

Psicodinámica del Trabajo del Grupo de Profesionales de la Educación de Escuelas Públicas

\begin{abstract}
Resumen
Teniendo en cuenta el contexto actual de la educación básica pública brasileña, el presente estudio tuvo como objetivo investigar las estrategias de movilización colectiva de un equipo de profesionales de la educación de una escuela primaria de la red de educación pública del Distrito Federal de Brasil, desde la perspectiva psicodinámica del trabajo, que considera tal movilización como un medio para replantear la experiencia de sufrimiento en placer en el trabajo. Se utilizó la metodología dejouriana y fueron realizadas observaciones no sistemáticas, análisis documental y seis sesiones colectivas con 12 trabajadores - maestros de escuela, profesores en desvío de función y orientadora educacional - de una misma escuela. Puede concluirse que las estrategias de defensa son, en su mayoría, individuales y que la movilización colectiva entre los profesionales de diferentes tareas se ve afectada por la falta de un espacio público de discusión, donde puedan discutirse las angustias y placeres del día a día de trabajo. Palabras clave: Trabajo, educación, escuela.
\end{abstract}

\section{Introdução}

A educação formal no Brasil se tornou um direito prescrito na Constituição Federal de 1988 pelo artigo 205, e também dever de todos - Estado e família - sendo necessário o incentivo e colaboração da sociedade com vistas de, pela educação, promover o desenvolvimento dos cidadãos brasileiro e qualificá-los para o mercado de trabalho. Contudo, não é incomum ver notícias em todo o país sobre os níveis de analfabetismo funcional e a falta de mão de obra qualificada. É conhecido de todos que o contexto da educação pública brasileira encontra-se precarizado e que, além dos prejuízos para os alunos, também gera prejuízos àqueles que se dedicam ao trabalho nesse contexto (Hypolito, 2011).

Muita atenção tem sido dada em diversas abordagens para o estudo do trabalho dos profissionais da educação, especialmente dos docentes de escola pública, contudo pouco se tem investigado acerca dos outros profissionais envolvidos nesse contexto e sua interação com os docentes - auxiliares administrativos, orientadores educacionais, merendeiras, o que pode vir a dificultar a compreensão da dinâmica do trabalho dentro da escola. Considerando que o trabalhar, como ação, se dá nas relações intersubjetivas dos envolvidos no contexto (Mendes, 2007), é importante olhar para 
além do docente para buscar a compreensão do trabalho na escola.

Os trabalhos encontrados sobre o tema do trabalho na escola relatam o sofrimento no exercício do magistério, focando a relação professor-aluno-pais, deixando subentendido a noção de que o trabalho na escola se realiza apenas em sala de aula. Não foram encontrados trabalhos voltados para a compreensão do trabalho em equipe que envolve o fazer escolar, ou seja, analisando a relação entre professores em sala de aula, como também com orientação educacional e funções administrativas.

Embora a "área fim" da educação seja realizada dentro da sala de aula - onde se passam as informações, conteúdos, em que se dá o contato com os alunos é necessária a estrutura de uma "área meio" e de um suporte pedagógico para que esse trabalho seja realizado de maneira mais eficiente, especialmente, frente ao novo contexto social do qual provém grande parte da clientela das escolas públicas. Nesse novo cenário, demanda-se à escola não só a educação formal, mas também a atenção a problemas sociais e econômicos que interferem no desempenho dos estudantes (Barbosa, 2009).

A conceituação de quem são esses profissionais da educação ainda merece reflexão. Enquanto o trabalho do docente consiste em passar conteúdos e prover essa educação formal conforme prescrito em lei, o orientador educacional, por exemplo, seria responsável pelo apoio da atividade pedagógica, e aos profissionais envolvidos com a biblioteca e laboratório de informática, por exemplo, seriam atribuídas as funções de conceber projetos pedagógicos complementares ao trabalho de sala de aula. O número de estudos voltados para a investigação do trabalho do professor regente em diversas abordagens - ergonomia, sociologia, enfermagem - é notadamente maior que o dos outros profissionais, e apontam para a precariedade da organização desse trabalho e dos danos físicos, psíquicos e sociais que pode causar (Almeida, Neves, \& Santos, 2010; Araújo \& Carvalho, 2009; Assunção \& Oliveira, 2009; Souza \& Leite, 2011)

Com relação aos outros profissionais das escolas, entre os poucos estudos produzidos, está o de Souza, Rozemberg, Santos, Yasuda e Sharapin (2003) com o apoio do sindicato dos profissionais de educação do Rio de Janeiro. Os autores investigam as profissionais que trabalham com a merenda e os serventes como profissionais da educação. $\mathrm{O}$ estudo visou à criação de um produto comunicacional - um mural informativo sobre a saúde desses trabalhadores a ser disponibilizado nas escolas - por professores, merendeiras e serventes. Esse material foi elaborado em conjunto, a partir de encontros coletivos onde os participantes discutiram suas vivências e compreensão do trabalho de merendeira. Essa investigação revelou as merendeiras como profissionais isoladas e que não estão cientes de seus direitos, e mostra o desconhecimento por parte dos outros profissionais da escola acerca do trabalho delas.

Os diferentes profissionais envolvidos no trabalho escolar parecem ser investigados separadamente, sendo que os estudos com foco no coletivo de trabalho constituído tanto pelos que estão em sala de aula quanto pelos que estão fora dela não foram encontrados. Segundo a Psicodinâmica do trabalho, abordagem multidisciplinar desenvolvida na França pelo médico e psicanalista Christophe Dejours nos anos 80, é impossível compreender o trabalho e o trabalhador isolados - "trabalhar é viver junto". Para os teóricos dessa abordagem que estuda a inter-relação do trabalhador com a organização do trabalho, o modo como as tarefas são divididas, os tempos e ritmos estabelecidos para um grupo de trabalho, os modos operatórios prescritos e efetivos sugerem a constituição de relações hierárquicas que podem favorecer o prazer ou o sofrimento, a saúde ou a doença no trabalho (Dejours, Abdoucheli, \& Jayet, 1994)

Ainda nessa perspectiva, o sofrimento e o prazer constituiriam uma relação dialética, sendo que o sofrimento é produto dos obstáculos que se interpõe entre o trabalho prescrito - o ideal, que deveria ser feito - e o real - o efetivo, o que pode ser feito perante essas limitações. Diante desse impasse, os trabalhadores lançam mão de estratégias de defesa individuais ou coletivas, ou da mobilização subjetiva, que permitem a transformação do prazer em sofrimento (Mendes, 2007).

Contudo, para que possa haver esse movimento em busca do prazer, é necessário que haja, na organização do trabalho, uma dinâmica de reconhecimento, de contribuição-retribuição simbólica, que permita ao trabalhador estabelecer espaços de discussão pública e deliberação, que valorize o uso da inteligência prática, além de privilegiar o estabelecimento de relações cooperativas entre os indivíduos (Mendes, 1995). Dessa forma, é que idealmente se constituiria um coletivo de trabalho. Este é definido como um coletivo que se constrói com base em um grupo de regras que não estão prescritas, mas que são acordadas pelos trabalhadores, conforme se relacionam entre si e com seu trabalho. Essas normas não prescritas têm uma dimensão ética e estética definida por aqueles que formam o 
coletivo. A partir desse coletivo de normas, é possível o uso de estratégias de mobilização coletiva, viabilizando a construção de novas formas de gerir a organização do trabalho e de produzir mudanças concretas no estabelecimento da organização.

Dois trabalhos que utilizam a abordagem psicodinâmica do trabalho que se destacam pelo foco no estudo de coletivos de trabalho são o de Lima (2011), com cuidadores sociais de um abrigo de crianças e adolescentes no estado do Rio de Janeiro, e o de Santos-Junior, Mendes e Araújo (2009) com uma equipe multiprofissional de trabalhadores de um Centro de Atenção Psicossocial. O primeiro tem como um dos objetivos compreender a construção do coletivo desses trabalhadores, e o segundo, busca um entendimento mais generalizado, procurando compreender as vivências de prazer e sofrimento na equipe investigada. Um dos achados de Santos-Junior et al. (2009) indica que a composição multiprofissional da equipe interfere na organização do trabalho, especialmente no modo como se dão as relações socioprofissionais e divisão de tarefas, contudo, isso não é aprofundado tendo em vista que não se caracteriza como um dos objetivos de seu estudo. Outro apontamento desse trabalho é da importância do reconhecimento entre os pares e aproximação do trabalho do outro para que a cooperação e constituição efetiva do coletivo ocorram, o que também é descrito por Lima (2011) em sua tese, enfatizando que o fortalecimento do coletivo de trabalho junto com o reconhecimento do profissional parece ser o caminho para o prazer nas tarefas realizadas no contexto do trabalho desses profissionais.

Partindo do pressuposto que "trabalhar é viver junto", como compreender o trabalho dos profissionais da educação, suas vivências de prazer e sofrimento, se não visualizando seu trabalho em relação ao trabalho dos outros profissionais da escola, como professores, orientadores educacionais, gestores, bibliotecários, técnicos, entre outros? Olhar para o trabalho na escola como além de sala de aula mostra-se essencial para compreender, não só o funcionamento da escola, como também os destinos de todos os trabalhadores envolvidos, do coletivo de trabalho.

O presente estudo teve como objetivo analisar a psicodinâmica do coletivo de trabalho, por meio da investigação da mobilização coletiva de uma equipe de profissionais de educação de uma escola de ensino fundamental da rede pública do Distrito Federal, considerando a organização do trabalho, as vivências de prazer-sofrimento e as estratégias de defesa utilizadas por eles, como sujeitos e como grupo, no cotidiano de trabalho na escola. Para este trabalho, serão considerados como profissionais da educação todos aqueles envolvidos em funções relacionadas diretamente às atividades pedagógicas - como professores e orientadores.

\section{Método}

\section{Participantes}

Foram entrevistados 12 profissionais da educação - nove professores em regência de classe, duas professoras em desvio de função, sendo uma na biblioteca e outra no laboratório de informática, e uma orientadora educacional - todos com média de 15 anos de profissão e há, pelo menos, um ano na mesma escola.

\section{Procedimentos}

O processo de pesquisa desenrolou-se conforme preconizado por Dejours (1992), descrito em três etapas: 1) pesquisa inicial - que envolve o recebimento e análise da demanda, o recrutamento dos participantes, os ajustes necessários entre pesquisador e interessados. É o momento em que se investiga a organização real do trabalho; 2) a pesquisa propriamente dita - que envolve a coleta de material a partir dos encontros coletivos com o grupo de trabalhadores em que se utiliza a fala como principal fonte de dados, além das observações clínicas feitas a respeito da dinâmica do grupo; 3) a validação e refutação dos dados - que é feita ao fim do processo de coleta, levando-se aos sujeitos um relatório dos dados coletados para que possam fazer suas considerações acerca do material e das interpretações feitas pelo pesquisador.

A direção de uma escola de ensino fundamental do Distrito Federal demandou uma intervenção voltada para as relações interpessoais dos profissionais da escola ao sindicato dos professores no Distrito Federal, com o qual o Laboratório de Psicodinâmica e Clínica do Trabalho da Universidade de Brasília mantém parceria. Uma pesquisadora foi encaminhada à escola para apresentar a proposta de pesquisa-ação. Todos os profissionais da escola, independentemente de suas funções, foram convidados a participar de uma reunião onde a proposta seria exposta.

Ao final da apresentação, uma lista foi disponibilizada para que os interessados mantivessem contato para uma segunda reunião em que seriam determinados locais e recursos necessários para que a pesquisa fosse realizada. Nesse momento posterior, foi apresentando ainda o termo de consentimento livre e 
esclarecido, que garantia aos participantes o sigilo de suas informações além do caráter voluntário de suas participações, podendo se retirar do grupo a qualquer momento sem prejuízos.

Os próprios trabalhadores escolheram horário e local conveniente para a realização da pesquisa e foram realizadas seis sessões semanais com a participação de uma pesquisadora e, em média, dez trabalhadores, com duração entre uma hora e meia e duas horas em horário de trabalho, conforme acordado com a gestão da escola e os próprios participantes, que se ordenaram para não atrapalhar o andamento das atividades pedagógicas na escola. Os encontros aconteceram na sala da orientadora educacional, onde os participantes dispuseram de 13 cadeiras posicionadas em círculo.

O primeiro encontro, conforme prescrito no método dejouriano, iniciou-se com a solicitação por parte da pesquisadora para que cada um se apresentasse e falasse sobre o seu trabalho. Como sugerido no método, não há roteiro de entrevista ou um instrumento específico, seguindo-se o fluxo das informações trazidas pelos participantes. A clínica do trabalho na abordagem da psicodinâmica do trabalho, o processo aqui descrito, é que se constitui como o instrumento.

As falas eram anotadas conforme eram ditas, em forma de notas e, ao fim de cada encontro, era feito o registro clínico da sessão, contendo breve resumo de conteúdos e interpretações a serem retomados no início do encontro seguinte. No sexto encontro, a validação e refutação dos dados obtidos foram feitas, conforme descrito por Dejours (1992). Para realizar a validação, foi elaborado relatório tanto sobre a trajetória do grupo dentro da prática quanto sobre os conteúdos que descreviam a organização do trabalho e as relações dos participantes.

\section{Análise}

Os dados obtidos foram analisados de acordo com a segunda etapa do método de Análise Clínica do Trabalho (Mendes \& Araújo, 2012), que classifica os resultados em três eixos temáticos - organização do trabalho prescrito e o real do trabalho; mobilização subjetiva e sofrimento, defesas e patologias - de acordo com as categorias teóricas da psicodinâmica do trabalho.

\section{Resultados}

No eixo I - organização do trabalho - o primeiro ponto relevante para se compreender a dinâmica do grupo foi a diversidade do conteúdo das tarefas de cada um dos cargos ali representado, uma vez que o grupo foi formado por profissionais de diferentes áreas e que têm atribuições distintas no contexto escolar. Os professores em regência, por exemplo, trouxeram o relato de que o professor deve ensinar, passar os conteúdos e buscar atender a demanda de educação feita pela sociedade, também cabendo a eles o desempenho de tarefas, como preenchimento de relatórios, diários, preparação de aulas, exercícios, provas e participação em projetos extracurriculares - além de ter de gerenciar o ambiente de sala e a relação com os pais dos alunos. Já no relato da orientadora educacional, aparecem outras atividades especialmente relacionadas a atender as demandas psicossociais da comunidade escolar - pais e alunos, enquanto as professoras em desvio de função ocupavam-se de atividades na biblioteca e no laboratório de informática, atendendo os alunos e professores. Todas as tarefas relatadas, nas diversas funções profissionais na escola, foram relacionadas aos alunos e pais, sempre focando na necessidade de atender a comunidade como um todo, por meio do ensino e das atividades promovidas pela equipe profissional da escola. Ficou claro, no discurso dos profissionais, que o trabalho na escola não é mais apenas relacionado à educação formal, mas nota-se uma mudança no papel dos trabalhadores em função das mudanças sociais, especialmente no que se refere a alguns papeis antes vistos como familiares e agora desempenhados dentro da escola ("a gente tem que ser tudo na escola. Não é só passar informação.”).

Os trabalhadores da escola também fazem referência às influências políticas em seus trabalhos, apontando para a mudança de governo como intrinsecamente ligada ao tipo de controle exercido sobre seus trabalhos e a organização destes, apontando para a descontinuidade de políticas públicas e aparecimento constante de novas prescrições de trabalho que não se adéquam ao cotidiano de seus trabalhos ("quando entrou aquele lá pra governador, mudou tudo, vieram uns funcionários dele e aí qualquer coisa que se fazia eles falavam 'olha, você tá no sal, viu!'. É só mudar o governo que muda tudo.”). O tempo na escola é descrito como uma "roda viva" em que tudo acontece muito rápido, mas em contrapartida o tempo parece se arrastar dentro de sala de aula, em que se passam "200 dias letivos com os mesmos alunos, com os mesmos problemas". $\mathrm{Na}$ escola, vive-se o mesmo tempo dos alunos, em que o calendário dos profissionais da escola anda junto com o calendário letivo, independentemente de suas atribuições. Em função desse tempo, alguns profissionais 
dessa escola apresentam um ritmo acelerado e relatam se sentir sempre conectados aos acontecimentos da escola mesmo quando estão fora dela.

As relações socioprofissionais na escola aparecem como um tema-chave para compreender a demanda do grupo, que aponta para essa questão como uma grande, não só na escola, mas na secretaria de educação em geral ("existem duas escolas dentro dessa escola, são as panelinhas (...) mas não é só aqui. Já trabalhei em outras que eram muito piores"). Existe um sentimento de desamparo, especialmente relacionado ao início de carreira, seja pela defasagem na formação - que não abrange o cotidiano, as questões que estão além da teoria - ou pela falta de um programa da secretaria de educação para inserir os novos professores no sistema ("quando você chega é tudo diferente, a gente não aprende na faculdade a lidar com os alunos, com o emocional. Sem contar que, quando você entra, a secretaria de educação te joga no sistema de qualquer jeito. Quando vê, já tem que ir pra escola, entrar na sala, dar aula").

Em um ambiente que está sempre em movimento e repleto de gente, os profissionais muitas vezes se sentem sozinhos, mostrando que as relações socioprofissionais na categoria são difíceis de se estabelecerem, havendo receio até mesmo de buscar ajuda por parte de alguns, que sentem que "quem pede ajuda demais, acaba sendo bombardeado", sendo considerado incompetente, indicando que, dentro do meio profissional da educação, o trabalhador deve ser autossuficiente para responder seus próprios anseios ("se você pede muita ajuda pro outro, você passa por incompetente. O professor tem que se virar mesmo (...) O bom professor é aquele que não dá trabalho, que dá conta de tudo dentro da sala"). Na escola, diz-se ainda que há muita informação circulando o tempo todo em pouco tempo entre muitas pessoas, sendo que, por diversas vezes, algumas informações não chegam a quem deveria chegar, o que também atrapalha a execução das tarefas dos trabalhadores ("é muita coisa acontecendo e, se você perde uma informação, já era”).

Com relação aos pais e alunos, os profissionais parecem estabelecer vínculos afetivos que trazem possibilidades para que o prazer seja vivenciado na escola. Contudo, é também na relação com os alunos que os trabalhadores aqui sentem uma das maiores dores: a da impotência. Quando se deparam com o fracasso escolar, tendem a se sentir culpados por esses fracassos, indicando a percepção de que o desempenho do profissional da educação está relacionado diretamente ao desempenho individual de cada aluno.
A respeito da relação com a gestão da escola, os participantes do grupo indicam que o desempenho da equipe está também relacionado ao tipo e a qualidade de relação estabelecida com ela, sendo que suas motivações, desempenhos e possibilidade de buscar estratégias de mobilização estão relacionadas a esse modo de gestão. Uma gestão com menos espaço para diálogo e sem comunicação devida das informações é vista como mais difícil de trabalhar, como um obstáculo para a realização do trabalho ("quando a direção te ouve, tá do seu lado, é outra coisa, o trabalho flui melhor”). O grupo aponta para a importância da proximidade entre direção, coordenação e corpo docente, sendo que todos devem trabalhar com um objetivo comum, que é, de acordo com o grupo, atender ao aluno.

No eixo II - mobilização subjetiva - o trabalho na escola é descrito como um lugar repleto de oportunidades para que se superem desafios dia após dia, seja dando "jeitinhos" na falta de recursos, como projetores de imagem e equipamento audiovisual, como pela marca que cada um deixa no trabalho que faz. Esse jeito de cada um desempenhar suas tarefas e de dar vida ao trabalho faz com que, no grupo, haja frequentes relatos sobre como determinada pessoa faz sua tarefa de um jeito único e inconfundível ("quando eu vejo o jeito como um aluno fala, eu já sei que ele é aluno daquele professor". "Sem ela lá, a biblioteca não funciona, não é a mesma coisa. Lá tem a carinha dela"). Contudo, diz-se que, formalmente, na escola, não há espaços para discutir esses aspectos voltados para a experiência do trabalho que foram abordados durante os encontros da pesquisa. Fala-se também que as reuniões para coordenação de atividades destinam-se a tratar do pedagógico e do administrativo com professores regentes, coordenação e direção da escola, sem incluir os outros cargos. Nos espaços informais - conversas entre colegas, não planejadas - há dificuldade para articular a fala do coletivo em função da existência de pequenos grupos dentro da escola, que muitas vezes divergem na opinião, o que dificultaria o diálogo entre os profissionais pelo sentimento de falta de abertura por parte dos outros e também pela própria falta de abertura aos outros, não só para falar, mas também para ouvir.

No grupo, nota-se maior presença de relações de cooperação entre os professores regentes, mas, ainda assim, com dificuldades na questão de solicitar auxílio ou buscar os colegas para opiniões ou conversas a respeito de dificuldades no trabalho. Nota-se que, em função, muitas vezes da dificuldade de lidar com a impotência, os trabalhadores, especialmente os 
professores regentes, isolam-se com medo de transparecer vulnerabilidades, muitas vezes dando sinais de que não precisam do outro, escondendo receios e sofrimentos advindos do exercício profissional dos colegas. Os outros profissionais - orientadora educacional, profissional da biblioteca e do laboratório de informática, por exercerem funções ímpares no contexto escolar, encontram dificuldades de estabelecer diálogos e relação de cooperação com os professores regentes, havendo pouca ou quase nenhuma percepção de que as funções profissionais de cada um estão intrinsecamente ligadas. São inseridas constantemente falas que apontam para um coletivo fragmentado, indicado pela sensação dos participantes de que existem dentro da escola, na verdade, duas ou três escolas que se caracterizam pelas "panelinhas" e suas crenças em como se deve realizar o trabalho e quais resultados devem buscar.

Apesar de conviverem no mesmo espaço muito tempo, frequentemente falta tempo ou um momento para parar e (re)conhecer o trabalho dos colegas ("é tudo tão corrido dentro da escola que você não tem tempo nem pra conhecer o colega da sala do lado, aí você entra na sala dos professores e é só falando sobre aluno"), especialmente o daqueles que não estão em sala de aula. Contudo, o reconhecimento começa a surgir no grupo a partir da prática de pesquisa realizada, que viabilizou um espaço de escuta, permitindo que os trabalhadores pudessem entrar em contato com o relato dos colegas e, assim, também pudessem perceber que, na escola, há um mundo maior que a sala dos professores e que atravessava as fronteiras da sala de aula.

No eixo III - sofrimentos, defesas e patologias - os profissionais relataram que as situações de dificuldade na escola, como a falta de recursos e as dificuldades nas relações, são vistas, não só como obstáculos, mas são vividas em alguns momentos como ponto de partida para mobilização, seja dentro ou fora da escola. As dificuldades, quando encaradas como desafios, são o ponto de partida para a vivência do prazer no trabalho.

Contudo, como já dito antes, uma das maiores angústias no âmbito da educação é a dificuldade em lidar com a impotência perante as questões que surgem no cotidiano de trabalho. A falta de recursos materiais, como diferente do esperado, não é o fator que mais causa sofrimento no trabalho, mas sim as dificuldades em aceitar que não se pode controlar tudo dentro do trabalho, como, por exemplo, o comportamento dos alunos dentro de sala de aula ("parece que o aluno vem pronto pra te bombardear") e a carência da comunidade que frequenta a escola ("aí você vê qual o problema do aluno: o pai do menino tá preso, a mãe tem que trabalhar fora o dia todo pra sustentar o menino e aí ele fica na rua, sabe-se lá com quem”), que faz com que se sintam sempre divididos entre o ressentimento com o aluno e a compaixão por ele. A orientadora profissional e as professoras em desvio de função mostram-se mais afetadas pela questão da carência da comunidade e pela burocracia, dita excessiva, nos processos cotidianos que tem de realizar - no caso da orientadora, por exemplo, encaminhar alunos para avaliações e para o conselho tutelar e, no caso das professoras em desvio de função, a conciliação de horários de atividades e o acesso a recursos materiais. A dificuldade em estabelecer relações em que se sintam à vontade dentro do coletivo de trabalho para se colocarem e mobilizarem-se também é relatada como um sofrimento ("você se sente abandonado, como se navegasse em alto mar em um barquinho de papel").

A resistência surge como defesa quando se tenta explorar mais a fundo o tema das relações interpessoais, havendo, nas primeiras entrevistas, discursos repetitivos sobre a culpa do aluno no sofrimento do professor, destacando o sentimento de solidão dentro das salas de aula e um sentido de que o trabalho na escola acontece principalmente em sala de aula ("tudo cai em cima do professor, tudo é culpa do professor”). A negação do adoecimento, também, é frequente. Há dificuldade entre os profissionais para tratar desses temas, dizendo que preferem ir trabalhar doentes a faltarem. O humor para falar do sofrimento no trabalho e a racionalização da doença e do sofrimento, dizendo-se muitas vezes que haveria sempre a opção de buscar outra escola, outra regional ou outro emprego, também, estavam presentes nos discursos de todos os profissionais ("se não tiver gostando é simples, é só fazer um outro concurso pra outra coisa e pronto (...) Se você não gosta da escola, porque ficar lá se pode mudar?"). Outra estratégia que também apareceu por parte de alguns foi buscar momentos de descontração e aproximação pessoal com colegas para poder lidar com o trabalho e fazer atividades diferentes da rotina ("se entre as aulas eu não parasse e desse uma conversadinha com ela [outra professora], falar de novela, essas coisas, eu já estaria em depressão"). Nota-se que as estratégias de defesa individuais estão favorecidas em detrimento das coletivas.

Algumas das patologias mencionadas como frequentes na categoria em geral e temidas por muitos foram a depressão e os transtornos de ansiedade. A ansiedade parece bastante comum no meio, o que se nota pela fala acelerada e volume de atividades em 
que cada um se engaja, indicando algumas vezes um investimento excessivo por não saberem lidar com a impotência e com a questão do fracasso escolar discente. Aparecem, em função do trabalho, algumas dificuldades na relação familiar e com amigos, em função da dificuldade em se desconectar do trabalho da escola. Ao longo da prática, acompanhou-se uma reestruturação dos discursos dos sujeitos, surgindo falas de reconhecimento dos pares ("eu nunca tinha parado pra pensar no trabalho da colega. Só sabia o nome dela. E aqui eu parei pra pensar o quanto é importante o trabalho dela", "eu estive pensando, e a gente podia continuar fazendo isso aqui quando a pesquisadora for embora. Isso de parar e conversar um pouco dessas coisas do trabalho, arranjar um tempo pra gente") e sobre o adoecimento no trabalho ("a gente tem que parar e olhar pra gente. Não dá pra dar conta de tudo sozinho ou, então, a gente fica doente mesmo, a gente tem que se cuidar"').

\section{Discussão}

Os resultados encontrados apontam para a dificuldade de se estabelecer um coletivo de trabalho entre professores e outros profissionais da escola em função das diferentes rotinas e poucos espaços compartilhados na escola. Discute-se abaixo, com estudos sobre a questão do coletivo de trabalho, a importância da construção deste com base, não só na complementaridade de diversas funções e cargos no local de trabalho, mas, sobretudo, pelo compartilhamento das vivências de prazer e sofrimento a partir de um espaço público de discussão entre os trabalhadores.

Para os docentes, um dos maiores sofrimentos está no fracasso escolar - quando um aluno é reprovado - conforme também encontrado no trabalho de Grande (2009). A esse acontecimento da reprovação, os professores quase sempre relacionam o seu potencial profissional como causa. No discurso da orientadora profissional e das professoras em desvio de função, encontram-se essas diferenças com relação às vivências de prazer e sofrimento, sendo que, na primeira, o sentimento de isolamento e solidão é relatado com frequência em função da singularidade das tarefas que lhe são atribuídas, e, nas professoras em desvio de função, há o fator relacionado à adaptação ao novo cargo e aos espaços que têm para socializar suas vivências com o grupo, corroborando com a observação de Santos-Junior et al. (2009) de que as diferentes funções e profissões na organização do trabalho impactam diretamente no estabelecimento das relações socioprofissionais. Esses são dados relevantes do presente trabalho - as diferenças encontradas nas maneiras e nos tipos de fatos e fatores, de acordo com seus cargos e atribuições, e a relação com a vivência de prazer e sofrimento no trabalho - que estão de acordo com a premissa da teoria da psicodinâmica do trabalho que relaciona a organização do trabalho ao prazer e o sofrimento no trabalho (Rossi, 2008).

A dificuldade de estabelecer um espaço de discussão é atribuída pelo grupo à rotina corrida na escola, como já relatado por Grande (2009) e à distância entre as funções que exercem. Com isso, buscam estratégias defensivas individuais, a despeito das coletivas, com o sentido de aplacar e abafar o sofrimento ao invés de ressignificá-lo, o que pode levar ao adoecimento e sintomas já relatados pelos participantes. Consequentemente, com a dificuldade de constituir o coletivo e superar as barreiras do silêncio, é difícil e raro que a dinâmica do reconhecimento e a cooperação surjam entre os trabalhadores de diferentes cargos, havendo maior coesão entre professores regentes, que se reconhecem como grupo, uma vez que tendem a se identificar mais facilmente uns com os outros em função de suas atribuições semelhantes.

Conforme visto no estudo de Grande (2009), também, com professores de uma escola pública do Distrito Federal, os professores falam de um "reconhecimento velado" por parte dos colegas, um reconhecimento que nunca é verbalizado. Isso também foi encontrado nesse grupo que viu no momento de pesquisa, segundo os próprios participantes, a oportunidade de declarar esse reconhecimento que não encontra tempo ou espaço para ser falado no cotidiano do trabalho. Silva e Mendes (2012) observaram o mesmo tipo de movimento de abertura e constituição de espaço público de discussão, ao longo de uma prática de clínica do trabalho, com servidores de uma agência reguladora, em que os sujeitos começam a se conscientizar pelo e no espaço de fala que necessitam mobilizar-se coletivamente para dar conta do trabalho.

Souza et al. (2003) também apontam para o espaço de fala como emancipador do sujeito em relação a sua condição no trabalho, além de potencializador da constituição de um coletivo em que os sujeitos se colocam ativamente sobre suas vivências de trabalho, como ocorreu ao longo do processo desta pesquisa. Espaço esse de grande importância para compartilhamento de informações sobre direitos e deveres, mas, sobretudo, para a criação de um vínculo 
entre os sujeitos que os conecte intersubjetivamente a partir de uma noção de alteridade.

É somente a partir da percepção de um sofrimento comum - a impotência perante a maneira como se estrutura o sistema educacional e social em que estão inseridos - que o grupo começa, de fato, a discursar como grupo, escutando uns aos outros - e não só ouvindo, como ação física e automática - e se reconhecendo nas angústias e prazeres relatados, especialmente no que concerne à relação com o aluno, que representa fonte de alegrias e tristezas para todos os profissionais participantes. Assim como observou Lima (2011), é com a consciência de que tem um objetivo e um objeto comum - o aluno e a relação com ele, no caso desses profissionais participantes da pesquisa - é que se inicia o desvelamento das contribuições de cada um dos participantes para que esse trabalho seja realizado e, adiante, uma estruturação de um coletivo aconteça, havendo uma compreensão de que a escola é mais do que sala de aula e conteúdo, e de que o trabalho é mais que produção, é, sobretudo, relação com os outros.

O presente trabalho permite, ainda, contemplar possíveis relações entre a dinâmica do reconhecimento e a mobilização coletiva, sendo praticamente impossível haver a segunda sem que a primeira esteja em ação. Com isso, conclui-se que não foram encontrados indícios de mobilização coletiva a princípio, porém, com o passar dos encontros, a veiculação da palavra, no grupo, fez uma rede de reconhecimento e apoio serem construídas a partir da empatia de uns com os outros.

\section{Considerações Finais}

Com base nos resultados, pode-se afirmar que as estratégias de mobilização coletiva da equipe de profissionais da educação estudada são precárias, sendo marcadas pelo uso de defesas individuais, dificultando, assim, a mobilização como um meio de ressignificar as vivências de sofrimento em prazer no trabalho. Em relação à aplicação do método dejouriano, identificam-se algumas dificuldades em relação à análise da demanda, inicialmente mostrando-se institucional e, só ao longo do processo, aparecendo como também demanda do coletivo para estabelecer relações de cooperação no grupo de trabalhadores. O desinteresse inicial dos profissionais pode ainda ser explicado pela descrença na eficácia de intervenções externas e, também, pela sobrecarga de trabalho e ritmo acelerado em que vivem.

Com esses participantes, também, pôde-se acessar um dos fatores que parece dificultar a realização de pesquisas e outras atividades relacionadas à saúde mental: o preconceito relacionado ao tema, como observado no estudo de Silva, Brito, Neves e Athayde (2007), em que os participantes recorrem a uma série de recursos para evitar o tema da saúde-adoecimento. Nesse grupo, quando se observa mais a fundo, encontra-se que o receio de falar de saúde no trabalho envolve diretamente o receio de descobrir-se doente - ou pior que isso, descobrir-se vulnerável, não onipotente. De descobrir-se humano.

É necessário, ainda, destacar que o presente trabalho limita-se pela constituição de sua amostra, prioritariamente formada por professores em regência, e, também, por ser fruto do atendimento a uma demanda específica de um grupo que já apresentava queixas relacionadas a dificuldades nas relações socioprofissionais. Outra limitação a ser observada é que nem toda escola disponibiliza de um serviço específico de orientação educacional, bibliotecas e/ou laboratórios de informática, o que pode alterar significativamente as vivências de prazer e sofrimento e estratégias defensivas preferenciais dos profissionais desses outros contextos e do coletivo de trabalho.

Uma possibilidade de novo estudo seria a inserção de funcionários que trabalham em outras áreas da escola, como o serviço administrativo, a coordenação e os serviços de limpeza e segurança da escola, por exemplo. Outra demanda que surgiu a partir da realização deste trabalho foi de compreender a psicodinâmica do trabalho dos profissionais de orientação educacional, representada, neste estudo, por uma participante altamente engajada em um movimento de orientadores educacionais, que comunicava constantemente a necessidade de acolher esses profissionais da maneira como se estava acolhendo o grupo daquela escola.

Como recomendação, sugere-se o uso da clínica brasileira de psicodinâmica do trabalho como prescrita por Mendes e Araújo (2012), buscando integrar, por meio de dispositivos clínicos da escuta qualificada, com base na Psicanálise, a pesquisa e a ação. Essa perspectiva clínica tem como foco o processo de perlaboração e a transferência como caminhos para os sujeitos se apropriarem, de modo coletivo, do sofrimento e das defesas, para reconstruir coletivamente novas regras do fazer e do viver junto. Para tal, é fundamental o papel da supervisão e a ênfase na formação do clínico que, nessa perspectiva, passa a exercer o papel de clínico-pesquisador e, não mais, de pesquisador-clínico. 


\section{Referências}

Almeida, M. R. de, Neves, M. Y., \& Santos, F. A. dos. (2010). As condições e a organização do trabalho de professoras de escolas públicas. Psicologia: Teoria e Prática, 12(2), 35-50.

Araújo, T. M. de, \& Carvalho, F. M. (2009). Condições de trabalho docente e saúde na Bahia: Estudos epidemiológicos. Educação e Sociedade, 30(107), 427-449.

Assunção, A. A., \& Oliveira, D. A. (2009). Intensificação do trabalho e saúde dos professores. Educação e Sociedade, 30(107), 349-372.

Barbosa, S. J. (2009). A intensificação do trabalho docente na escola pública (Dissertação de mestrado). Universidade de Brasília, Brasília, Distrito Federal, Brasil.

Dejours, C. (1992). A loucura do trabalho: Estudo de psicopatologia do trabalho. São Paulo: Cortez.

Dejours, C., Abdoucheli, E., \& Jayet, C. (1994). Psicodinâmica do trabalho: Contribuições da escola dejouriana à análise da relação prazer, sofrimento e trabalho. São Paulo: Atlas.

Grande, C. (2009). O trabalho e o afeto: Prazer e sofrimento no trabalho dos professores da escola pública de Brasilia (Dissertação de mestrado). Universidade de Brasília, Brasília, Distrito Federal, Brasil.

Hypolito, A. M. (2011). Reorganização gerencialista da escola e trabalho docente. Educacão: Teoria e Prática, 21(38), 59-78.

Lima, S. C. C. (2011). Coletivo de trabalho e reconhecimento: Uma análise psicodinâmica dos cuidadores sociais (Tese de doutorado). Universidade de Brasília, Brasília, Distrito Federal, Brasil.

Mendes A. M., \& Araujo, L. K. R. (2012). Clínica psicodinâmica do trabalho: $O$ sujeito em ação. Curitiba: Juruá.

Mendes, A. M. (1995). Os novos paradigmas de organização do trabalho: Implicações para a saúde mental do trabalhador. Revista Brasileira de Saúde Ocupacional, 23(85-86), 55-60.

Mendes, A. M. (Org.) (2007). Psicodinâmica do trabalho: Teoria, método e pesquisas. São Paulo: Casa do Psicólogo.

Rossi, E. Z. (2008). Análise psicodinâmica do processo de reabilitação por LER/DORT em bancários (Tese de doutorado). Universidade de Brasília, Brasília, Distrito Federal.

Santos Junior, A. V., Mendes, A. M., \& Araújo, L. K. R. (2009). Experiência em clínica do trabalho com bancários adoecidos por LER/DORT. Psicologia Ciência e Profissão, 29(3), 614-625.

Silva, E. F. S., Brito, J., Neves, M. Y., \& Athayde, M. (2007). A promoção da saúde a partir das situações de trabalho: Considerações referenciadas em uma experimentação com trabalhadores de escolas públicas. Interface - Comunicação, Saúde, Educação, 13(30), 107-119.

Silva, M. C. S. Q., \& Mendes, A. M. B. (2012). A prática em clínica psicodinâmica do trabalho como estratégia de promoção da saúde. Revista Tempus-Actas de Saúde Coletiva, 6(2), 195-207.

Souza, A. N. de, \& Leite, M. de P. (2011). Condições de trabalho e suas repercussões na saúde dos professores da educação básica no Brasil. Educação e Sociedade, 32(117), 1105-1121.

Souza, K. R., Rozemberg, B., Santos, A. K., Yasuda, N., \& Sharapin, M. (2003). O desenvolvimento compartilhado de impressos como estratégia de educação em saúde junto a trabalhadores de escolas da rede pública do Estado do Rio de Janeiro. Cadernos de Saúde Pública, 19(2), 495-504.

Recebido: 05/08/2013

$1^{a}$ reformulação: 16/04/2014

$2^{a}$ reformulação: $24 / 06 / 2014$

Aprovado:10/12/2014 
Nota das autoras:

As autoras agradecem a CAPES e ao CNPq pelo apoio financeiro e ao sindicato dos professores do Distrito Federal pelo apoio institucional.

Sobre as autoras:

Fernanda Sousa Duarte é psicóloga e mestre em Psicologia Social, do Trabalho e das Organizações pela Universidade de Brasília. Atualmente é pesquisadora convidada do Laboratório de Psicodinâmica e Clínica do Trabalho.

Ana Magnólia Mendes é professora do Instituto de Psicologia da Universidade de Brasília e pós-doutorada no Conservatoire National des Arts et Métiers (CNAM), Paris. Atualmente coordena o laboratório de Psicodinâmica e Clínica do Trabalho da Universidade de Brasília.

\section{Contato com as autoras:}

Universidade de Brasília, Brasília

Instituto Central de Ciências - Campus Darcy Ribeiro

A1-49, Ala Sul, Brasília - DF

E-mail:nanda.sduarte@gmail.com 